\title{
BMJ Global Health Delivering comprehensive HIV services across the HIV care continuum: a comparative analysis of survival and progress towards $90-90-90$ in rural Malawi
}

Emily B Wroe, ${ }^{1}$ Elizabeth L Dunbar, ${ }^{1}$ Noel Kalanga, ${ }^{2}$ Luckson Dullie, ${ }^{1}$ Chiyembekezo Kachimanga, ${ }^{1}$ Andrew Mganga, ${ }^{3}$ Michael Herce, ${ }^{4}$ Jason Beste, ${ }^{5}$ Jonas Rigodon, ${ }^{6}$ Lawrence Nazimera, ${ }^{7}$ Ryan K McBain ${ }^{8}$

To cite: Wroe EB, Dunbar EL, Kalanga $\mathrm{N}$, et al. Delivering comprehensive HIV services across the HIV care continuum: a comparative analysis of survival and progress towards $90-90-90$ in rural Malawi. BMJ Glob Health 2018;3:e000552. doi:10.1136/ bmjgh-2017-000552

\section{Handling editor Sanni Yaya}

Received 5 September 2017 Revised 26 November 2017 Accepted 27 November 2017

\section{(a) CrossMark}

${ }^{1}$ Partners In Health, Neno, Malawi

${ }^{2}$ Health Systems and Policy, College of Medicine, Blantyre, Malawi

${ }^{3}$ Department of HIV and AIDS, Ministry of Health, Lilongwe,

Malawi

${ }^{4}$ Division of Infectious Diseases, University of North Carolina School of Medicine, Chapel Hill, North Carolina, USA

${ }^{5}$ Partners In Health, Harper, Liberia

${ }^{6}$ Haiti Delegation, American Red Cross, Port-au-Prince, Haiti ${ }^{7}$ Ministry of Health, Neno, Malawi

${ }^{8}$ Partners In Health, Boston, Massachusetts, USA

Correspondence to Dr Emily B Wroe; emwroe@gmail.com

\section{ABSTRACT}

Introduction Partners In Health and the Malawi Ministry of Health collaborate on comprehensive HIV services in Neno, Malawi, featuring community health workers, interventions addressing social determinants of health and health systems strengthening. We conducted an observational study to describe the HIV care continuum in Neno and to compare facility-level HIV outcomes against health facilities nationally.

Methods We compared facility-level outcomes in Neno $(n=13)$ with all other districts ( $n=682)$ from 2013 to 2015 using mixed-effects linear regression modelling. We selected four outcomes that are practically useful and roughly mapped on to the 90-90-90 targets: facility-based HIV screenings relative to population, new antiretroviral therapy (ART) enrolments relative to population, 1-year survival rates and per cent retained in care at 1 year.

Results In 2013, the average number of HIV tests performed, as a per cent of the adult population, was $11.75 \%$, while the average newly enrolled patients was $10.03 \%$. Percent receiving testing increased by $4.23 \%$ over 3 years $(\mathrm{P}<0.001$, $95 \% \mathrm{Cl} 2.98 \%$ to $5.49 \%$ ), while percent enrolled did not change $(P=0.28)$. These results did not differ between Neno and other districts $(\mathrm{P}=0.52)$, despite Neno having a higher proportion of expected patients enrolled. In 2013, the average ART 1-year survival was $80.41 \%$ nationally and $91.51 \%$ in Neno, which is $11.10 \%$ higher $(\mathrm{P}=0.002,95 \% \mathrm{Cl} 4.13 \%$ to $18.07 \%$ ). One-year survival declined by $1.75 \%$ from 2013 to $2015(\mathrm{P}<0.001,95 \% \mathrm{Cl}-2.61 \%$ to $-0.89 \%)$; this was similar in Neno ( $P=0.83)$. Facility-level 1-year retention was $85.43 \%$ nationally in $2013(\mathrm{P}<0.001,95 \% \mathrm{Cl} 84.2 \%$ to $86.62 \%)$ and $12.07 \%$ higher at $97.50 \%$ in Neno $(\mathrm{P}=0.001,95 \% \mathrm{Cl} 5.08 \%$ to19.05\%). Retention declined by $2.92 \%(\mathrm{P}<0.001,95 \% \mathrm{Cl}$

$-3.69 \%$ to $-2.14 \%$ ) between 2013 and 2015 , both nationally and in Neno.

Conclusion The Neno HIV programme demonstrated significantly higher survival and retention rates compared with all other districts in Malawi. Incorporating community health workers, strengthening health systems and addressing social determinants of health within the HIV programme may help Malawi and other countries accelerate progress towards 90-90-90.

\section{Key questions}

What is already known about this topic?

- Numerous studies have explored progress towards the Joint United Nations Programme on HIV/AIDS 90-90-90 targets, which could be framed as an HIV-oriented extension of the universal health coverage movement as they focus on quality across the HIV care continuum.

- However, these studies rely on infrequent and population-based surveys, and there is a need for a more practical approach to programme monitoring.

- Many studies have advocated for HIV programmes to include comprehensive services, such as community health workers and different forms of psychosocial and economic support, but evaluations of comprehensive programmes with these components are limited.

\section{What are the new findings?}

- Our study suggests that HIV programmes focusing on social determinants of health, community health workers and direct support to ministries of health may increase survival and retention for patients with HIV.

- We also introduce a practical approach for programme monitoring, using components aligned with the 90-90-90 targets.

\section{Recommendations for policy}

- As governments strive towards achieving the 90-90-90 targets and universal health coverage, it is worth considering policies integrating HIV programming in primary healthcare via support of the public sector and strong community footprints, and adopting approaches that address basic health systems needs and the social determinants of health.

\section{INTRODUCTION}

In 2015, the Government of Malawi committed to the Joint United Nations Programme on 
HIV/AIDS (UNAIDS) goal known as 90-90-90: $90 \%$ of HIV-positive patients diagnosed, $90 \%$ of those diagnosed sustained on treatment and $90 \%$ of those on treatment achieving viral suppression-all by 2020. ${ }^{1}$ However, robustly measuring progress towards these targets relies on expensive and infrequent population-based surveys, which may not always be practical for local programmes or in routine service delivery settings. ${ }^{2}$ Given the recognition that achieving 90-90-90 will require a health system strengthening approach involving local governments and civil society partners, there is a need for a more practical, programme-oriented approach for local monitoring. ${ }^{3}$ The 90-90-90 targets can help programmes measure success and make targeted improvements to HIV services in the spirit of achieving universal health coverage (UHC), ${ }^{4}$ given the focus on providing high-quality care for every patient with HIV in a given population.

Malawi's pursuit of 90-90-90 is particularly important given the context: it is one of only nine countries with HIV prevalence exceeding 9\%, and in 2015 only half of those affected were receiving treatment-approximately 500000 people. ${ }^{56}$ As a landlocked, mountainous country with limited supply chains and infrastructure, and having severe resource constraints commensurate with the fourth lowest gross domestic product (GDP) per capita in the world, acquisition and distribution of antiretroviral therapy (ART) to these individuals are highly challenging. ${ }^{7}$ However, Malawi has progressive policies, clear commitment and strong central leadership in the HIV programme: Malawi was the first country to initiate Option $\mathrm{B}+$, placing all HIV-positive pregnantwomen on ART, regardless of CD4 count. ${ }^{9}$ In 2016, the national HIV programme adopted the WHO recommendations for universal treatment. ${ }^{10}$ One study by Medecins sans Frontieres in Chiradzulu District in southern Malawi showed that a high level of population viral suppression is possible in this setting. ${ }^{11}$

Working towards 90-90-90 targets requires both national commitment as well as innovation in service delivery. Throughout the AIDS epidemic, multiple approaches and debates have been advanced as a means to achieve ART coverage and epidemic control, including those highlighting the tension between HIV integration within primary care versus more vertical HIV interventions, and facility-oriented versus community-oriented models. ${ }^{12}$ For the latter, many community-based programmes have used community health workers (CHWs) to increase retention in care for HIV-positive adults and children and HIV-exposed infants. ${ }^{13-17}$ In addition, economic support to offset treatment costs and address underlying poverty has been put forward in the form of cash transfers, and programmes including food packages have shown higher rates of adherence. ${ }^{18-21}$ Since 2007, Partners In Health (PIH) and the Malawi Ministry of Health (MOH) have been collaborating in one of the country's poorest districts-Neno District-to implement an innovative HIV/AIDS service delivery model, grounded in decentralised care and a strong community footprint. ${ }^{22-24}$ This programme is founded on a long history of PIH's work in partnership with governments and communities globally. ${ }^{1225}{ }^{26}$ An extensive literature demonstrates that a community-based service delivery platform employing CHWs is effective in providing patients with psychosocial accompaniment, adherence support, longitudinal follow-up and missed visit tracking. ${ }^{27-30}$ It also addresses social determinants of disease-meaning social and economic conditions that can influence differences in health status-as part of a comprehensive package. ${ }^{27} 28$ Furthermore, to promote sustainability, the model is integrated within the Malawi $\mathrm{MOH}$ systems to strengthen primary healthcare, an approach that has also been used in Haiti and Rwanda. ${ }^{125}$

In this manuscript, we characterise the HIV care continuum in Neno District, and compare facility-level HIV outcomes between the Neno programme and all other health facilities nationally to estimate impact. Specifically, we describe programme performance over a 3-year period (2013-2015) according to the 90-9090-aligned outcomes along the HIV care continuum, comparing outcomes from Neno District facilities with all other Malawian facilities. We describe the results for HIV screening, enrolment, retention and survival, describing outcomes over time to interrogate consistency and robustness of observed effects to secular trends. We also describe our programme practices and interventions, which encompass establishing a strong community footprint, addressing the social determinants of health and advancing true partnerships with the public sector.

\section{METHODS}

\section{Setting and study population}

Since 2007, the Malawi MOH in collaboration with PIHknown locally as Abwenzi Pa Za Umoyo-have instituted a novel, community-based HIV care programme in Neno District. Neno District covers a catchment area of 1469 $\mathrm{km}^{2}$ in Malawi's south-west zone and is home to an estimated 150841 people in $2015 .{ }^{31}$ It represents one of the poorest and most rural districts in the country, with no tarmac roads, the majority of the population relying on subsistence agriculture and only $3.7 \%$ having electricity. ${ }^{32}$

For our study, we included all 13 health facilities in Neno District, including 1 district hospital, 1 community hospital and 11 primary health centres, all of which have been providing free HIV care since 2011. For the comparative analysis, we included all facilities in Malawi providing HIV care, comprising 29 districts and 682 facilities-which, including Neno, represents over 4800000 HIV screening events and 370000 new ART enrolments. In Malawi, $84 \%$ of the population is rural. ${ }^{31}$

\section{Neno HIV programme design}

The novelty of the Neno District HIV programme resides in three core principles, each rooted in the concept of accompaniment-or supporting the entirety of needs of the patient-with a focus on delivering services in a 
community-oriented way with the intention to reduce structural barriers to successful treatment:

1. A strong community footprint: A network of 900 paid, trained and mentored CHWs, living in the communities they serve, work with 6-10 patients with HIV, on average, focusing on psychosocial support, promotion of ART adherence and side effect monitoring, and tracking and accompanying clients to facilities. The CHWs act as 'foot soldiers' to the $\mathrm{MOH}$ cadre of health surveillance assistants (HSA), who have higher population coverage (1 HSA per roughly 1775 population vs 1 CHW per 168) and broader job descriptions. ${ }^{33}$ The community activities also feature a community support initiative that provides community-based psychosocial support through support groups for those affected by HIV.

2. A focus on social determinants of health: A socioeconomic assessment is performed for each patient in order to determine their level of poverty and specific needs. This assessment enables microeconomic interventions for vulnerable patients in the forms of non-conditional cash transfer, payment of school fees for children and addressing housing needs. In 2015, approximately $15 \%$ of ART patients received direct assistance such as cash transfers (average US\$23.3), with an additional 30\% receiving indirect assistance such as school or vocational support (average US\$10.9). Additionally, a nutrition support programme provides food packages for a period of 4 months to all patients initiating ART.

3. Partnership with the $\mathrm{MOH}$ to strengthen primary and secondary healthcare systems: $\mathrm{MOH}$ and $\mathrm{PIH}$ leadership, both based permanently in Neno District, work together to identify needs and fill gaps, with PIH employing a broad-based health systems strengthening approach. For example, PIH employs clinical staff for daily direct care delivery jointly supervised with $\mathrm{MOH}$ : in 2015 approximately one-third of clinical staff in Neno were employed by PIH. In addition, PIH helps construct and maintain infrastructure and acts as a backstop for essential medicines. Additionally, PIH supports a district-wide electronic medical record (EMR) system that collects patient-level clinical details and triggers a process for tracking clients who miss an appointment.

\section{Data collection}

The central $\mathrm{MOH}$ aggregates HIV data from all health facilities providing HIV care throughout Malawi on a quarterly basis, including Neno District. We chose a study period from Q1 2013 to Q4 of 2015, for several reasons: (1) this represented the broadest time range for which data were available for all facilities in Neno; (2) indications for ART initiation were constant; and (3) because the number of ART-providing facilities nationally had stabilised following substantial decentralisation in 2011 and 2012 following introduction of Option B+.
During 2013-2015, national policy mandated all HIV-positive patients with CD4 $\leq 500$ cells $/ \mathrm{mm}^{3}$ or WHO stage 3 or 4 (regardless of CD4 count) be enrolled in ART, in addition to all HIV-positive pregnant women and children under 5 years confirmed HIV-positive. ${ }^{34}$ Thus, the following were the study inclusion criteria: (1) a positive diagnosis of HIV and (2) enrolment in the national ART programme between 1 January 2013 and 30 December 2015. All facilities outside Neno providing HIV care in Malawi during this time period were chosen as comparison facilities. Fidelity to enrolment protocols and quality of data were monitored both centrally during quarterly $\mathrm{MOH}$ supervision at the facility level and through routine data validation..$^{35}$

\section{Measures}

We developed HIV programme performance metrics aligned with the UNAIDS 90-90-90 targets $^{36}$ that evaluated finding, enrolling and achieving high-quality outcomes in both known and undiagnosed expected patients with HIV in a given adult population. Thus, for case finding, we evaluated the number of total HIV tests performed in a district for those aged $>15$ years, over the course of a year, represented as relative to the number of individuals over the age of 15 in the catchment area. For successful enrolments, we measured the per cent of the catchment population newly enrolled in HIV care on an annual basis among those expected to be HIV-positive based on district population prevalence. ${ }^{37}$

For both metrics, the number of new screenings and new enrollees was selected, rather than cumulative total, in order to measure district-level improvement in the care continuum over time. However, in districts that were closer to achieving these targets at baseline, it is likely that screenings and enrolments decelerate-as new HIV-positive individuals become harder to find and enrol. Thus, we also report on the proportion achieved for anticipated full enrolment and the yield of HIV testing for Neno and nationally. We used the highest estimate of 1100000 expected people living with HIV (PLHIV) in Malawi in 2015 and applied district-level HIV prevalence estimates from the 2015-2016 Demographics and Health Survey. ${ }^{32}$

For the quality and success of treatment, in place of viral suppression used for the third 90, we elected to measure the average 1-year survival and retention rates at the facility level within districts. In many sub-Saharan African contexts, including Malawi, viral load results are not routinely available-largely because this depends on testing and supply chain systems for which a majority of facilities are not yet equipped. This limitation in routine viral load results includes Neno until system improvements and GeneXpert testing were introduced in late 2016. In such contexts, quality of care can be more broadly assessed in terms of patient survivorship and their routine return to facilities to acquire medicines to continue treatment. 


\section{Statistical analysis}

We examined statistical power to detect a medium effect size $(\delta=0.50)$ when comparing facility-level trends within Neno district versus all facilities throughout all other districts, over a 3-year period. Assuming a standard $\alpha$ level of 0.05 , a sample of 682 facilities, intracluster correlation coefficient for district-level clustering of $<0.05$ and serial correlation of $\mathrm{r}=0.50$, statistical power was greater than $80 \%$ to detect the effect size of interest.

We used mixed-effects, multilevel models to evaluate HIV outcomes across districts and to compare performance in Neno District versus all other districts. Random effects were incorporated for facilities and districts, whereby facilities were nested within districts and districts were nested within years. Fixed effects were included for Neno District and for specific years, in order to examine change in 2014 and 2015, relative to the baseline year of 2013. The interaction term of interest was Neno $\times$ year, which examined whether change over time on outcomes of interest was greater in Neno District compared with other districts. As a secondary set of analyses, we incorporated two sets of demographic district-level covariates: namely, the percentage of individuals in the district who are female and the percentage of households with electricity-as a proxy for district-level wealth, taken from the 2015-2016 Demographics and Health Survey. ${ }^{32}$ Neither covariate had any substantive impact on the results. We therefore chose to report primary models throughout in order to aid interpretability. Analyses were conducted in STATA V.13.0 SE.

\section{Patient involvement}

This was an observational study, and patients were not involved in the study design.

\section{RESULTS}

\section{Descriptive characteristics of sample}

From January 2013 through December 2015, 4869503 screenings for HIV were performed at facilities throughout Malawi. Over this same period, 368046 individuals aged 15 and over were newly enrolled in the HIV programme. The average 1-year survival among new ART enrollees at the facility level was $79.5 \%$, and the per cent retained in care at 1 year was $83.9 \%$. Table 1 presents an overview of this information at the district level on an annual basis.

\section{Performance over time}

Case finding

At baseline in 2013, the estimated proportion of the adult population who underwent HIV testing at a health facility was $11.75 \%(\mathrm{P}<0.001,95 \%$ CI $10.53 \%$ to $12.96 \%)$. This was $3.94 \%$ higher in Neno District $(15.69 \%)$, but the difference was not statistically significant $(\mathrm{P}=0.24,95 \%$ CI $-2.61 \%$ to $10.49 \%$ ). Over the 3 -year period, the average per cent of the population in all districts receiving HIV screening increased by $4.23 \%$ ( $\mathrm{P}<0.001,95 \%$ CI $2.98 \%$ to
$5.49 \%)$. This trend towards improvement over time was not significantly different in Neno $(\mathrm{P}=0.52,95 \%$ CI $-8.98 \%$ to 4.52 ). The yield of HIV testing in Neno was different from the yield nationally: Over the 3-year period, the national positivity rate among screenings was $6.91 \%(\mathrm{P}<0.001,95 \% \mathrm{CI} 5.84 \%$ to $7.98 \%)$; this was $1.35 \%$ lower in Neno District ( $\mathrm{P}=0.01,95 \% \mathrm{CI}-2.42 \%$ to $-0.29 \%)$. Table 2 shows these outcomes by district over the 3-year period.

\section{Enrolments}

In 2013, the average per cent of total expected HIV-positive adults (ages 15 and over) who were newly enrolled in ART during that year-based on national HIV prevalence-was $12.42 \%(\mathrm{P}<0.001,95 \%$ CI $10.54 \%$ to $14.30 \%)$. New enrolment levels were not significantly higher in Neno District ( $\mathrm{P}=0.56,95 \% \mathrm{CI}-13.12 \%$ to $7.13 \%)$. From 2013 to 2015, annual enrolment levels did not change nationally $(\mathrm{P}=0.17,95 \% \mathrm{CI}-0.22 \%$ to $1.74 \%)$. This trend was similar in Neno District $(\mathrm{P}=0.78,95 \% \mathrm{CI}-3.42 \%$ to $4.56 \%$ ). Table 2 shows the breakdown of these trends. However, progress towards total enrolment in Neno District exceeds the national average, and as of December 2015 Neno had enrolled $62.1 \%(n=7332$ of $n=11800)$ of the expected total district population of persons living with HIV, while nationally this was $54.7 \%$ ( $n=563203$ of $\mathrm{n}=1028$ 814) $(\mathrm{P}<0.001){ }^{32} 38$

\section{Survival}

At baseline, 1-year survival among those in quarterly cohorts was $80.41 \%$ ( $\mathrm{P}<0.001,95 \%$ CI $79.22 \%$ to $81.59 \%)$ across facilities within districts. Comparatively, survival was $11.10 \%$ higher in Neno District, at $91.51 \%(\mathrm{P}=0.002$, 95\% CI $4.13 \%$ to $18.07 \%$ ). Between 2013 and 2015, survival rates declined by $1.75 \% \quad(\mathrm{P}<0.001,95 \% \mathrm{CI}$ $-2.61 \%$ to $-0.89 \%)$. This was not significantly different in Neno District $(\mathrm{P}=0.83,95 \% \mathrm{CI}-6.60 \%$ to $5.33 \%)$ (table 3).

\section{Retention}

In 2013, 1-year retention among quarterly cohorts was $85.43 \%$ across all facilities within districts $(\mathrm{P}<0.001$, $95 \%$ CI $84.2 \%$ to $86.62 \%$ ). In Neno, this figure was $12.07 \%$ higher at $97.50 \%(\mathrm{P}=0.001,95 \%$ CI $5.08 \%$ to $19.05 \%)$. From 2013 to 2015 , retention levels declined nationally by $2.92 \%(\mathrm{P}<0.001,95 \% \mathrm{CI}-3.69 \%$ to $-2.14 \%)$. This trend was similar in Neno ( $\mathrm{P}=0.98,95 \% \mathrm{CI}-5.34 \%$ to $5.50 \%)$. Figure 1 provides an overview of results for survival and retention outcomes, and table 3 provides these outcomes by year.

\section{DISCUSSION}

We observed high total enrolment and 1-year survival and retention in care for ART-treated patients in Neno District, higher than all other districts nationally, suggesting the effectiveness of the Neno HIV programme across the HIV care continuum. These results were robust to secular trends and persisted over the entire 
Table 1 Average annual facility-level outcomes, by district (2013-2015)

\begin{tabular}{|c|c|c|c|c|c|}
\hline District & Population* & $\begin{array}{l}\text { Annual screenings } \\
\text { relative to adult } \\
\text { population† }(\%)\end{array}$ & $\begin{array}{l}\text { Annual new } \\
\text { enrolments relative to } \\
\text { expected patients with } \\
\text { HIV } ¥(\%)\end{array}$ & $\begin{array}{l}\text { 1-Year survival } \\
\text { for ART } \\
\text { patients§ (\%) }\end{array}$ & $\begin{array}{l}\text { 1-Year } \\
\text { retention } \\
\text { for ART } \\
\text { patients§ (\%) }\end{array}$ \\
\hline Balaka & 383887 & 10.8 & 12.0 & 78.2 & 82.1 \\
\hline Blantyre & 1239648 & 11.3 & 16.2 & 79.0 & 84.2 \\
\hline Chikwawa & 518287 & 12.2 & 11.5 & 80.3 & 85.3 \\
\hline Chiradzulu & 314059 & 10.6 & 17.8 & 81.9 & 85.4 \\
\hline Chitipa & 211170 & 10.8 & 4.7 & 79.8 & 86.2 \\
\hline Dedza & 718747 & 13.1 & 5.7 & 73.7 & 78.7 \\
\hline Dowa & 732342 & 8.0 & 3.5 & 82.2 & 85.7 \\
\hline Karonga & 327084 & 13.3 & 9.0 & 78.0 & 82.6 \\
\hline Kasungu & 794991 & 8.7 & 5.0 & $80.4 \%$ & 84.1 \\
\hline Likoma & 10440 & 8.5 & 6.1 & 65.9 & 76.9 \\
\hline Lilongwe & 2400234 & 12.4 & 9.5 & 78.7 & 82.3 \\
\hline Machinga & 589710 & 13.4 & 10.6 & 75.9 & 80.1 \\
\hline Mangochi & 982058 & 10.7 & 11.3 & 77.5 & 81.8 \\
\hline Mchinji & 569086 & 12.4 & 6.2 & 79.7 & 84.1 \\
\hline Mulanje & 564975 & 14.0 & 20.0 & 83.2 & 87.8 \\
\hline Mwanza & 102571 & 17.8 & 11.9 & 78.6 & 86.1 \\
\hline Mzimba North & 539148 & 13.4 & 11.2 & 81.5 & 84.8 \\
\hline Mzimba South & 539148 & 12.5 & 6.2 & 78.1 & 82.4 \\
\hline Neno & 143824 & 14.7 & 11.7 & 90.1 & 96.2 \\
\hline Nkhata Bay & 260583 & 11.2 & 8.6 & 77.3 & 81.4 \\
\hline Nkhotakota & 367776 & 12.2 & 8.0 & 78.6 & 82.8 \\
\hline Nsanje & 274797 & 17.0 & 17.9 & 73.2 & 76.1 \\
\hline Ntcheu & 557433 & 10.6 & 9.3 & 79.7 & 84.5 \\
\hline Ntchisi & 276481 & 11.4 & 3.3 & 79.8 & 84.5 \\
\hline Phalombe & 364281 & 15.6 & 18.3 & 84.0 & 86.8 \\
\hline Rumphi & 203054 & 18.7 & 9.9 & 80.6 & 85.1 \\
\hline Salima & 407148 & 11.2 & 8.2 & 77.4 & 80.1 \\
\hline Thyolo & 633019 & 16.1 & 15.7 & 83.8 & 88.0 \\
\hline Zomba & 779259 & 11.9 & 13.9 & 82.4 & 87.7 \\
\hline Total & 15805240 & 12.6 & 10.5 & 79.3 & 83.9 \\
\hline
\end{tabular}

*Population is based on district-level population in 2014, the midpoint of the study, as reported by the Malawi National Statistics Office. ${ }^{47}$ †Annual screenings represent the average annual number of the total HIV tests performed at facilities over the 2013-2015 study period in clients over age 15years, expressed as a per cent of the district population over the age of 15.

$\ddagger$ Annual enrolment is the average annual newly enrolled in ART between 2013 and 2015, expressed as a per cent of those estimated to be HIV-positive within a district.

§One-year survival and retention indicates the average annual facility-level 1-year survival and retention rates for patients on ART within each district between 2013 and 2015.

2013-2015 study period. While this study is not designed to estimate the relative impact of the components of our model, we postulate that a few unique aspects about the Neno HIV programme play critical roles in the results observed. First, the trained and paid cadre of CHWs enjoy low patient volume per CHW, allowing CHWs to do frequent routine-often daily-visits to support patient adherence, trace patients who missed visits, identify side effects or ill patients early, and flag any specific issues for the clinical staff. This is supported by literature advocating for CHWs for HIV programmes. ${ }^{14} 15272939$ This CHW system is backed up by a robust standard operating procedure for missed visit tracking: CHWs make up the first tier, and when that fails HIV clinic staff go out on motorbikes on a weekly basis to locate patients and bring them back to clinic where possible.

Second, given the impoverished population served, we posit that our focus on addressing social determinants 
Table 2 Average annual facility-level outcomes, by district, by year (screening and enrolment)

\begin{tabular}{|c|c|c|c|c|c|c|c|}
\hline \multirow[b]{2}{*}{ District } & \multirow[b]{2}{*}{ Population } & \multicolumn{3}{|c|}{$\begin{array}{l}\text { Annual screenings relative to the } \\
\text { adult population (\%) }\end{array}$} & \multicolumn{3}{|c|}{$\begin{array}{l}\text { Annual new enrolments relative to } \\
\text { expected patients with HIV (\%) }\end{array}$} \\
\hline & & 2013 & 2014 & 2015 & 2013 & 2014 & 2015 \\
\hline Balaka & 383887 & 10.8 & 7.8 & 13.8 & 11.8 & 12.7 & 12.4 \\
\hline Blantyre & 1239648 & 9.9 & 8.5 & 15.4 & 7.8 & 8.4 & 9.0 \\
\hline Chikwawa & 518287 & 11.2 & 8.3 & 17.2 & 12.5 & 14.8 & 14.4 \\
\hline Chiradzulu & 314059 & 9.3 & 8.9 & 13.6 & 16.2 & 19.7 & 16.9 \\
\hline Chitipa & 211170 & 11.1 & 7.6 & 13.8 & 13.9 & 13.4 & 13.6 \\
\hline Dedza & 718747 & 12.9 & 10.3 & 16.1 & 16.5 & 16.5 & 15.9 \\
\hline Dowa & 732342 & 7.9 & 6.5 & 9.5 & 9.3 & 9.2 & 8.2 \\
\hline Karonga & 327084 & 12.1 & 7.3 & 20.5 & 8.0 & 8.3 & 9.3 \\
\hline Kasungu & 794991 & 7.7 & 6.9 & 11.6 & 10.7 & 10.6 & 11.9 \\
\hline Likoma & 10440 & 8.4 & 12.0 & 5.1 & 6.8 & 13.0 & 2.7 \\
\hline Lilongwe & 2400234 & 11.7 & 10.9 & 14.6 & 11.2 & 12.5 & 12.3 \\
\hline Machinga & 589710 & 14.0 & 10.5 & 15.8 & 15.2 & 16.6 & 15.1 \\
\hline Mangochi & 982058 & 9.2 & 8.4 & 14.4 & 9.4 & 10.4 & 10.8 \\
\hline Mchinji & 569086 & 11.2 & 10.5 & 15.7 & 10.2 & 11.2 & 11.9 \\
\hline Mulanje & 564975 & 15.6 & 11.2 & 15.2 & 8.2 & 10.1 & 8.2 \\
\hline Mwanza & 102571 & 10.9 & 14.3 & 28.4 & 13.4 & 14.4 & 16.2 \\
\hline Mzimba North & 539148 & $13.4 \%$ & 10.2 & 16.7 & 26.6 & 29.7 & 31.4 \\
\hline Mzimba South & 539148 & 11.6 & 9.3 & 16.7 & 17.6 & 16.0 & 14.9 \\
\hline Neno & 143824 & 15.7 & 10.7 & 17.7 & 9.4 & 10.1 & 10.5 \\
\hline Nkhata Bay & 260583 & 11.9 & 9.5 & 12.2 & 12.6 & 13.1 & 10.9 \\
\hline Nkhotakota & 367776 & 9.5 & 9.7 & 17.2 & 9.6 & 9.5 & 10.7 \\
\hline Nsanje & 274797 & 16.6 & 13.1 & 21.2 & 14.6 & 13.5 & 15.5 \\
\hline Ntcheu & 557433 & 9.8 & 7.9 & 14.0 & 11.0 & 11.1 & 10.8 \\
\hline Ntchisi & 276481 & 11.1 & 9.0 & 14.1 & 6.4 & 6.6 & 6.9 \\
\hline Phalombe & 364281 & 15.9 & 12.0 & 18.9 & 11.6 & 10.5 & 10.2 \\
\hline Rumphi & 203054 & 16.6 & 13.2 & 26.4 & 12.9 & 15.2 & 15.5 \\
\hline Salima & 407148 & 9.9 & 9.2 & 14.5 & 21.9 & 26.9 & 26.1 \\
\hline Thyolo & 633019 & 18.3 & 9.8 & 20.3 & 13.0 & 11.9 & 11.3 \\
\hline Zomba & 779259 & 10.7 & 10.4 & 14.6 & 9.1 & 10.0 & 9.6 \\
\hline
\end{tabular}

of health is a critical piece, including the provision of food packages, cash transfers and inkind support to ART patients. Numerous studies support food packages as a means to optimising patient adherence. ${ }^{19-21}$ Additionally, as governments work towards UHC, finding mechanisms to reduce catastrophic health expenditures is important, ${ }^{4}$ with Neno District highlighting the use of social welfare interventions to mitigate the effects of poverty on our patients. Third, the approach in Neno District is characterised by the comprehensive spectrum of support by PIH, with a long-term commitment to key system inputs beyond technical assistance or capacity building. For example, as of 2016, PIH employs $34 \%$ of clinical staff doing direct care delivery and $66 \%$ of HIV programme staff, which has been consistent since 2013. ${ }^{40}$ Other examples include construction and maintenance of hospitals and clinics, backstopping the $\mathrm{MOH}$ formulary with procurement of essential medications and health commodities, supporting an EMR and data quality improvement initiatives, and purchasing critical medical equipment for the district. This approach is informed by and echoes the sentiments put forward in the global arena, such as the Declaration of Alma Ata, advocating for primary healthcare and the 2005 Paris Declaration on Aid Effectiveness on aligning aid to countries' priorities and local systems. ${ }^{4142}$

We also describe favourable population-level uptake of HIV screening and ART linkage in Neno District. While the annual number of ART enrolments observed in Neno is consistent with national trends, Neno District is farther along towards achieving full programme enrolment. As districts in Malawi strive towards complete case finding, 
Table 3 Average annual facility-level outcomes, by district, by year (survival and retention)

\begin{tabular}{|c|c|c|c|c|c|c|c|}
\hline \multirow[b]{2}{*}{ District } & \multirow[b]{2}{*}{ Population } & \multicolumn{3}{|c|}{ 1-Year survival for ART patients (\%) } & \multicolumn{3}{|c|}{ 1-Year retention for ART patients $(\%$} \\
\hline & & 2013 & 2014 & 2015 & 2013 & 2014 & 2015 \\
\hline Balaka & 383887 & 80.1 & 74.5 & 80.2 & 84.8 & 78.0 & 83.4 \\
\hline Blantyre & 1239648 & 80.4 & 79.9 & 77.1 & 85.5 & 85.0 & 82.5 \\
\hline Chikwawa & 518287 & 81.2 & 78.8 & 80.7 & 85.9 & 85.0 & 84.9 \\
\hline Chiradzulu & 314059 & 79.8 & 80.4 & 84.0 & 83.2 & 84.3 & 87.4 \\
\hline Chitipa & 211170 & 82.0 & 76.7 & 80.7 & 90.1 & 81.2 & 87.2 \\
\hline Dedza & 718747 & 76.6 & 72.9 & 71.7 & 82.0 & 77.7 & 76.4 \\
\hline Dowa & 732342 & 82.2 & 82.1 & 82.2 & 87.0 & 85.8 & 84.5 \\
\hline Karonga & 327084 & 79.7 & 80.1 & 74.4 & 85.1 & 83.5 & 79.2 \\
\hline Kasungu & 794991 & 81.7 & 78.7 & 80.8 & 85.8 & 81.7 & 84.7 \\
\hline Likoma & 10440 & 81.0 & 80.2 & 36.7 & 84.4 & 88.1 & 58.3 \\
\hline Lilongwe & 2400234 & 80.5 & 78.4 & 77.3 & 85.0 & 82.0 & 80.1 \\
\hline Machinga & 589710 & 74.5 & 75.0 & 78.0 & 80.0 & 78.9 & 81.2 \\
\hline Mangochi & 982058 & 77.2 & 76.7 & 78.6 & 81.9 & 81.5 & 82.1 \\
\hline Mchinji & 569086 & 81.8 & 77.7 & 79.6 & 87.1 & 81.5 & 83.6 \\
\hline Mulanje & 564975 & 83.0 & 83.0 & 83.6 & 89.3 & 86.9 & 87.3 \\
\hline Mwanza & 102571 & 75.9 & 80.9 & 78.8 & 87.7 & 87.4 & 83.3 \\
\hline Mzimba North & 539148 & 83.9 & 79.9 & 80.7 & 87.2 & 83.0 & 84.4 \\
\hline Mzimba South & 539148 & 80.3 & 78.4 & 76.1 & 84.1 & 83.2 & 80.0 \\
\hline Neno & 143824 & 92.1 & 89.1 & 89.0 & 98.2 & 95.8 & 94.6 \\
\hline Nkhata Bay & 260583 & 78.1 & 79.3 & 74.7 & 83.5 & 82.8 & 78.2 \\
\hline Nkhotakota & 367776 & 79.4 & 77.1 & 79.2 & 84.2 & 81.2 & 83.0 \\
\hline Nsanje & 274797 & 74.9 & 73.9 & 71.0 & 78.5 & 76.8 & 73.3 \\
\hline Ntcheu & 557433 & 80.5 & 79.9 & 78.6 & 85.7 & 84.7 & 83.0 \\
\hline Ntchisi & 276481 & 79.7 & 77.1 & 82.6 & 85.9 & 81.8 & 86.1 \\
\hline Phalombe & 364281 & 85.8 & 83.3 & 83.1 & 89.6 & 85.6 & 85.3 \\
\hline Rumphi & 203054 & 84.3 & 79.5 & 77.9 & 90.4 & 83.6 & 81.2 \\
\hline Salima & 407148 & 78.8 & 74.6 & 78.7 & 81.2 & 78.1 & 81.1 \\
\hline Thyolo & 633019 & 84.6 & 84.2 & 82.7 & 89.4 & 87.9 & 86.7 \\
\hline Zomba & 779259 & 82.5 & 82.3 & 82.3 & 89.1 & 87.6 & 86.3 \\
\hline
\end{tabular}

the yield of HIV testing in identifying new infections will decrease over time, and programmes will have to do more HIV testing and/or more targeted HIV testing to find new patients. These trends may have important considerations for programme design, in that traditionally 'high yield' has been a benchmarker for successful HIV testing programmes, but as countries move towards achieving the first 90, lower yields may in fact be a natural marker of success. This highlights the need for innovative and datadriven testing strategies to reach underserved PLHIV who do not yet know their status and who are being missed by more traditional facility-based testing strategies. The approach in Neno has been to operationalise HIV testing as a standard screening test at the community, outpatient department and inpatient levels, which in 2015-2016 had yields of $1.9 \%, 2.9 \%$ and $3.8 \%$, respectively. ${ }^{43}$ In addition to striving towards universal opt-out, inpatient testing services, Neno employs a programme called Screening for Health And Referral in the Community, an integrated screening programme that targets the most remote areas of the district, sending teams out twice weekly to screen community members for HIV, tuberculosis, malnutrition, hypertension and diabetes. Although the yield is smaller, this blanket approach could be a critical part to reaching full enrolment. Early experience shows that $22.7 \%$ of community members screened at these events had never previously been tested. ${ }^{44}$

The scalability and sustainability of this programme are contingent on a variety of factors. One of the most significant constraints is financing to support this model, as Malawi is one of the poorest countries in the world. We have published elsewhere on the cost-effectiveness of this model,${ }^{45}$ showing that a quality-adjusted life year gained-on average-from the model costs less than 


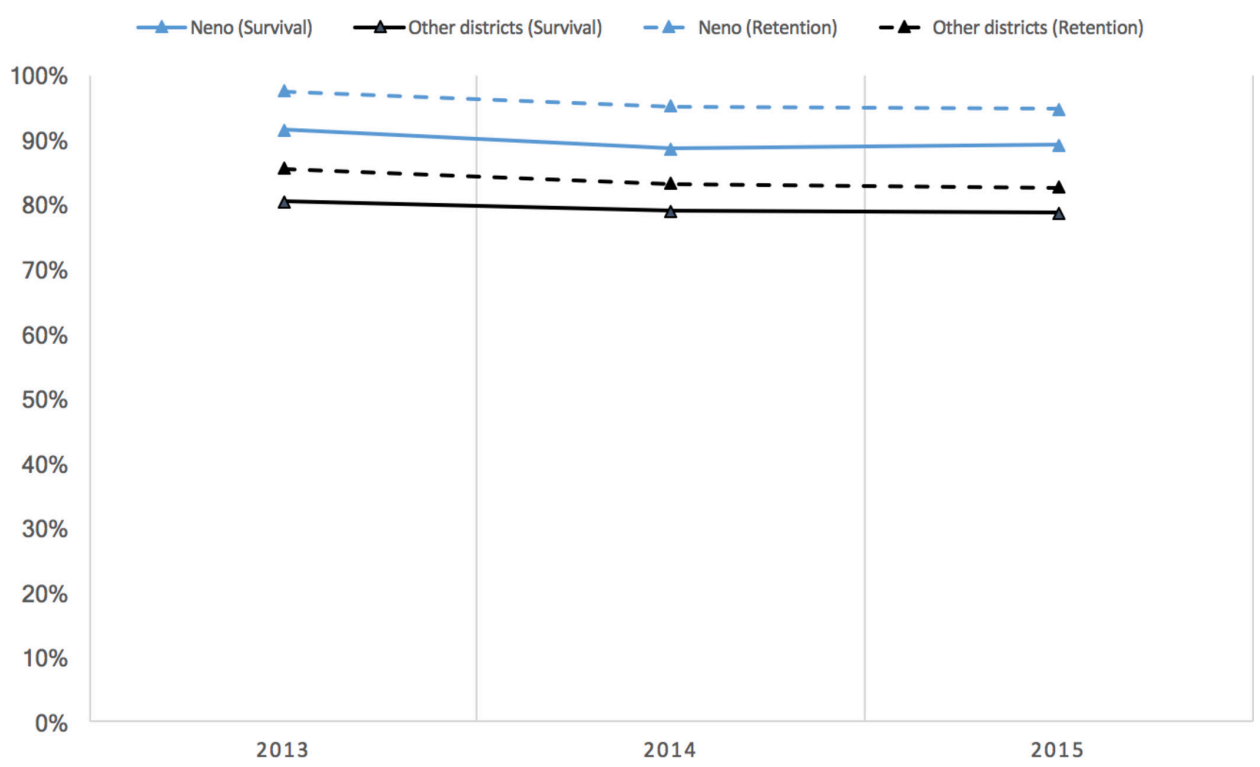

Figure 1 One-year survival and retention among newly enrolled patients with HIV, 2013-2015.

three times the GDP per capita, a traditional marker of cost-effectiveness. ${ }^{46}$ Beyond cost considerations are additional questions of scalability. In support of the scale-up enterprise, PIH has successfully expanded components of care models to regional and national levels in Rwanda ${ }^{25}$ and Lesotho. ${ }^{26}$ Findings reported in this study have also been presented to members of the parliament in Malawi, as well as members of the MOH. In the near term, our goal is to continue monitoring and demonstrating the success of this model and to engage in further health policy discussions.

There are a few key limitations to this study. First, district-level demographic covariates, such as age and gender distribution, were not included in the model as the analysis was done with national-level aggregate data, and HIV survival data were not disaggregated in Malawi by age and gender. Second, the outcomes do not map precisely on to the 90-90-90 targets, both because evaluating programmes by the first 90 without population-level data is challenging and because of the lack of complete viral load data for the district cohorts. As viral load testing becomes more routine and accessible, this will be a critical part of programme evaluation moving forward. We instead opted for a more practical and programme-oriented approach that uses robust proxy outcomes of survival and care retention to evaluate the programme and understand progress on themes of UHC and quality of care. Our analytical approach can be replicated in other resource-limited, high-burden settings to more regularly and rapidly assess HIV programme progress against national targets. Finally, given the retrospective nature of the data, as well as the utilisation of facility-level and district-level data instead of patient-level outcomes, we are limited in our ability to isolate the effect of certain programme components.

This study describes the results of an innovative model of district-wide partnership and HIV service delivery in Neno, demonstrating greater progress towards full HIV programme enrolment and higher 1-year patient retention and survival than national averages. Importantly, these effects have been maintained over at least a 3-year period. As governments strive towards meeting the 90-90-90 targets, we advocate for policies and practices (1) rooted in primary healthcare that tackle comprehensive and basic health system needs; (2) that leverage strong district-level partnership between non-governmental organisations and the public sector; (3) focused on strong community footprints; and 4) that pragmatically address the social determinants of health.

Acknowledgements There are numerous people who have contributed to the success of the HIV program in Neno District: former DHOs Felix Chingoli \& Jones Masiye; former PIH Malawi Executive Director Keith Joseph; MOH ART Coordinators Finala Phiri; CHW Program Manager Henry Makungwa; POSER Program Manager Victor Kanyema; Community Programs Manager Sam Njolomole; former PIH HIV \& Nutrition Program Manager Blessings Banda; current PIH HIV Manager Kondwani Nyangulu; the rest of the numerous $\mathrm{MOH}$ and PIH HIV program staff who work tirelessly to bring high quality HIV care to patients who need it most; and lastly all of our CHWs and our HIV patients who help us improve the program, best meet needs, and continue to strive for the best HIV outcomes possible in Neno District.

Contributors EBW, NK and ELD conceptualised the study. ELD, RKM and AM provided data curation and expertise, and RKM led data analysis and methodology. EBW, NK, LD, CK and LN provided programme contextualisation. MH, JB and JR provided additional technical expertise. EBW and RKM prepared the first draft of the manuscript, and all authors edited and reviewed the manuscript.

Funding HIV programme activities in Neno District are funded by private charity donors to Partners In Health.

Competing interests None declared.

Ethics approval We obtained IRB approval from Malawi's National Health Science Research Committee based in Lilongwe, Malawi, as well as Partners Healthcare Institutional Review Board in Boston, Massachusetts, USA. As no data were collected at the patient level, this study was exempt from full review.

Provenance and peer review Not commissioned; externally peer reviewed.

Data sharing statement All authors had full access to all of the data in the study and can take responsibility for the integrity of the data and the accuracy of the data analysis. Full data set and statistical code can be requested from the 
corresponding author at ewroe@pih.org. Aggregate facility-level data were used, and no patient-level data were part of this study.

Open Access This is an Open Access article distributed in accordance with the Creative Commons Attribution Non Commercial (CC BY-NC 4.0) license, which permits others to distribute, remix, adapt, build upon this work non-commercially, and license their derivative works on different terms, provided the original work is properly cited and the use is non-commercial. See: http://creativecommons.org/ licenses/by-nc/4.0/

(c) Article author(s) (or their employer(s) unless otherwise stated in the text of the article) 2018. All rights reserved. No commercial use is permitted unless otherwise expressly granted.

\section{REFERENCES}

1. UNAIDS. Malawi signs new agreement to boost response against AIDS, tuberculosis and malaria. 2015 http://www.unaids.org/en/ resources/presscentre/featurestories/2015/october/20151023_ malawi (cited 12 Jul 2017).

2. Gaolathe T, Wirth KE, Holme MP, et al. Botswana's progress toward achieving the 2020 UNAIDS 90-90-90 antiretroviral therapy and virological suppression goals: a population-based survey. Lancet HIV 2016;3:e221-30.

3. Barnhart S. PEPFAR: is $90-90-90$ magical thinking? Lancet 2016;387:943-4

4. Taverne B, Desclaux A, Delaporte E, et al. Universal health coverage and HIV in resource-constrained countries: a critical juncture for research and action. AIDS 2013;27:2173-5.

5. Joint United Nations Programme on HIV/AIDS. HIV prevalence. 2016 http://data.un.org/Data.aspx?q=hiv+prevalence\&d=UNAIDS\&f= inID\%3a36 (cited 1 Jul 2016).

6. Joint United Nations Programme on HIV/AIDS. Coverage of people receiving ART. 2016 http://data.un.org/Data.aspx?q=art+coverage\& $\mathrm{d}=$ UNAIDS\&f=inID\%3a133 (cited 1 Jul 2016).

7. World Bank. GDP per capita (current US\$). 2016 http://data. worldbank.org/indicator/NY.GDP.PCAP.CD?locations=MW\&year_ high_desc=false (cited 28 Feb 2017).

8. Chana R. Assessment of the logistics and supply chain management of anti-TB medicines. Arlington, VA: Management Sciences for Health, 2011.

9. WHO. Implementation of option B+for prevention of mother-tochild transmission of HIV: the Malawi experience. Brazzaville: WHO Regional Office for Africa, 2014.

10. WHO. Consolidating guidelines on the use of antiretroviral drugs for treating and preventing HIV infection. Geneva: WHO, 2016.

11. Maman D, Chilima B, Masiku C, et al. Closer to 90-90-90. The cascade of care after 10 years of ART scale-up in rural Malawi: a population study. J Int AIDS Soc 2016;19:20673.

12. Walton DA, Farmer PE, Lambert W, et al. Integrated HIV prevention and care strengthens primary health care: lessons from rural Haiti. J Public Health Policy 2004;25:137-58.

13. Mwai GW, Mburu G, Torpey K, et al. Role and outcomes of community health workers in HIV care in sub-Saharan Africa: a systematic review. J Int AIDS Soc 2013;16:18586.

14. Torpey KE, Kabaso ME, Mutale LN, et al. Adherence support workers: a way to address human resource constraints in antiretroviral treatment programs in the public health setting in Zambia. PLoS One 2008;3:e2204.

15. Marcos Y, Phelps BR, Bachman G. Community strategies that improve care and retention along the prevention of mother-to-child transmission of HIV cascade: a review. J Int AIDS Soc 2012;15(Suppl 2):17394.

16. Kim MH, Ahmed S, Preidis GA, et al. Low rates of mother-to-child HIV transmission in a routine programmatic setting in Lilongwe, Malawi. PLoS One 2013;8:e64979.

17. Kim MH, Ahmed S, Buck WC, et al. The Tingathe programme: a pilot intervention using community health workers to create a continuum of care in the prevention of mother to child transmission of HIV (PMTCT) cascade of services in Malawi. J Int AIDS Soc 2012;15(Suppl 2):17389.

18. McCoy SI, Njau PF, Czaicki NL, et al. Rationale and design of a randomized study of short-term food and cash assistance to improve adherence to antiretroviral therapy among food insecure HIV-infected adults in Tanzania. BMC Infect Dis 2015;15:490.

19. Xue J, Mhango Z, Hoffman IF, et al. Use of nutritional and water hygiene packages for diarrhoeal prevention among HIV-exposed infants in Lilongwe, Malawi: an evaluation of a pilot prevention of mother-to-child transmission post-natal care service. Trop Med Int Health 2010;15:1156-62.

20. Cantrell RA, Sinkala M, Megazinni K, et al. A pilot study of food supplementation to improve adherence to antiretroviral therapy among food-insecure adults in Lusaka, Zambia. J Acquir Immune Defic Syndr 2008;49:190-5.

21. van Oosterhout JJ, Ndekha M, Moore E, et al. The benefit of supplementary feeding for wasted Malawian adults initiating ART. AIDS Care 2010;22:737-42.

22. Wroe EB, Kalanga N, Mailosi B, et al. Leveraging HIV platforms to work toward comprehensive primary care in rural Malawi: the integrated chronic care clinic. Healthc 2015;3:270-6.

23. Herce ME, Elmore SN, Kalanga N, et al. Assessing and responding to palliative care needs in rural sub-Saharan Africa: results from a model intervention and situation analysis in Malawi. PLoS One 2014;9:e110457.

24. Herce ME, Kalanga N, Wroe EB, et al. Excellent clinical outcomes and retention in care for adults with HIV-associated Kaposi sarcoma treated with systemic chemotherapy and integrated antiretroviral therapy in rural Malawi. J Int AIDS Soc 2015;18:19929.

25. Lee S, Rhatigan J, Kim J, et al. HIV care in Rwanda. Cases in global health delivery. Cambridge: Harvard University, 2008.

26. In Lesotho, a new level of accompaniment. 2014 https://www.pih. org/article/expanding-a-proven-model-in-lesotho-to-save-lives

27. Rich ML, Miller AC, Niyigena P, et al. Excellent clinical outcomes and high retention in care among adults in a community-based HIV treatment program in rural Rwanda. J Acquir Immune Defic Syndr 2012;59:e35-42.

28. Mukherjee JS, Eustache FE. Community health workers as a cornerstone for integrating HIV and primary healthcare. AIDS Care 2007;19(Suppl 1):73-82.

29. Franke MF, Kaigamba F, Socci AR, et al. Improved retention associated with community-based accompaniment for antiretroviral therapy delivery in rural Rwanda. Clin Infect Dis 2013;56:1319-26.

30. Rigodon J, Joseph K, Keshavjee S, et al. Training community health workers to scale-Up HIV care in rural lesotho: implementation lessons from the field. World J AIDS 2012;02:135-42.

31. Malawi National Statistical Office. 2008 population and housing census: population projections. Malawi: Malawi National Statistical Office, 2008.

32. Malawi National Statistical Office. Malawi demographic and health survey, 2015-2016. Malawi: Malawi National Statistical Office, 2017.

33. Kok MC, Namakhoma I, Nyirenda L, et al. Health surveillance assistants as intermediates between the community and health sector in Malawi: exploring how relationships influence performance. BMC Health Serv Res 2016;16:164.

34. Ministry of Health. Clinical management of hiv infection in children and adults. Malawi: Ministry of Health, 2014

35. Jahn A, Harries AD, Schouten EJ, et al. Scaling-up antiretroviral therapy in Malawi. Bull World Health Organ 2016;94:772-6.

36. UNAIDS. 90-90-90: an ambitious treatment target to help end the AIDS epidemic. Geneva: UNAIDS, 2014.

37. UNAIDS. Population prevalence of HIVIAIDS. Geneva: UNAIDS, 2016.

38. UNAIDS. Malawi country fact sheet. 2017 http://www.unaids.org/en/ regionscountries/countries/malawi.

39. Bhutta ZAL, Pariyo G, Huicho L. Global experience of community health workers for delivery of health related millennium development goals: a systematic review, country case studies, and recommendations for integration into national health systems. Geneva, Switzerland: World Health Organization, 2010.

40. Partners in health and neno district ministry of health, internal discussion and analysis. 2016.

41. Declaration of Alma Ata. International conference on primary health care, Alma-Ata, USSR, 6-12. 1978 http://www.who.int/publications/ almaata_declaration_en.pdf

42. Paris declaration on aid effectiveness. 2005 http://www.oecd.org/ dac/effectiveness/34428351.pdf

43. Partners In Health, electronic medical record, htc monthly reports, results from July 2015-June 2016.

44. Partners In Health, Screening for Health and Referral in the Community (SHARC) database, internal data. (accessed Apr 2017).

45. McBain RK, Petersen E, Tophof N, et al. Impact and economic evaluation of a novel HIV service delivery model in rural Malawi. AIDS 2017;31:1999-2006.

46. WHO-CHOICE. Cost-effectiveness and strategic planning. http:// www.who.int/choice/cost-effectiveness/en/ (accessed Oct 2017).

47. National Statistics Office. Statistical yearbook 2015. Zomba, Malawi: National Statistics Office, 2015. 